\title{
PARTISIPASI KELOMPOK WANITA TANI DALAM MENINGKATKAN KAWASAN RUMAH PANGAN LESTARI DI NAGARI SAGO SALIDO KEBUPATEN PESISIR SELATAN
}

Rahayu Erita Putry ${ }^{1,}$ Karjuni Dt.Maani²

${ }^{1}$ Rahayu, Padang, Indonesia,

2Jurusan Ilmu Administrasi Publik, Fakultas Ilmu Sosial, Universitas Negeri Padang, Padang, Indonesia,

${ }^{3}$ Email : $\underline{\text { rahayueritaputri@gmail.com; }}$ dtmaani@yahoo.com

\begin{abstract}
Meeting the needs of food for the community in connection with increasing population and decreasing the number of agricultural areas. resulting in serious problems because the amount of food available is deficient. Based on this, a strategy that needs to be followed up to overcome the food crisis going forward. One of the efforts carried out by the government so far is to optimize the use of community houses as a source of family food. Food is a basic need for human survival, so everyone needs to be guaranteed to get quality and safe food. Food that is not produced properly and can be a source of microorganisms and chemical contaminants that can be dangerous and cause disease to humans. Cases of food poisoning should not need to occur if food products are processed with the correct processing procedures (Badan POM, 2007). Conditions for the fulfillment of food for the state up to individuals, as reflected in the availability of sufficient food, both in quantity and quality, safe, diverse, nutritious, equitable and affordable and not contrary to religion, beliefs, and culture of the community, to be able to live healthy, active, and productive in a sustainable manner (Law No. 18/2012).
\end{abstract}

Keywords: Food, Participation of Women Farmers Groups

\section{PENDAHULUAN}

Bagi manusia pangan merupakan kebutuhan dasar untuk kelangsungan hidup. Sehingga setiap orang harus dijamin dalam memperoleh pangan yang aman dan bermutu tinggi. Banyakna kebutuhan dan bahan pangan yang di produksi tidak secara baik dan benar dapat menjadi sumber mikroorganisme dan kontaminan kimia yang berbahaya dan menjadi penyebab penyakit kepada manusia. Terjadinya kasus-kasius keracunan pangan seharusnya tidak perlu terjadi apabila produk pangan diolah dengan prosedur pengolahan yang benar (Badan POM, 2007). 
"Berdasarkan buku Sumatera Barat dalam angka tahun(2018)jumlah penduduk miskin di Kabupaten Pesisir Selatan yang tercatat oleh Badan Pusat Statistik yaituberjumlah 34.920 orangatau $7,59 \%$ dari jumlah penduduk, , terlihat bahwa persentasependuduk miskin di Pesisir Selatan termasuk kelompok sedang. Seseorang disebut miskin karena tidak mampumemperolehpendapatan mencapai minimal Rp. 409.882 per kapital per bulan. Batas garis kemiskinan tahun 2018 sebesar Rp. 409.882 per kapital per bulan, atau mengalamikenaikan sebesar 4,84\% dibandingkanpendapatan per kapital per bulantahun 2017"

“Darianalisis terhadap data-datamasyarakat miskin di Pesisir Selatan, dapat ditarik kesimpulan bahwa penyebab kemiskinan merupakankombinasi antarakemiskinan yang disebabkan oleh pola hidup malas untuk berusaha dan sebagian karena tidak memiliki lahan usaha. Kemiskinan yangbersifat ketergantungan antara lain akibat tidak memiliki lahan usaha pertanian, Rata-rata kepemilikan lahansawah per keluarga di Pesisir Selatan hanya sekitar 0,28 hektar, atau 0,06 hektar per jiwa sehinggasangat tidak efisien untuk diusahakan."

Pertumbuhan ekonomi Kabupaten Pesisir selatan duatahun terakhir mengalami penigkatan yakni 5,27\% pada tahun 2016 naik menjadi 5,29\% tahun 2017. Pertumbuhan ekonomi di Pesisir Selatan pada tahun2017 yaitu 5,29\%, tingkat pengangguran terbuka (TPT) 5,95\%, penduduk miskin 7,79\%, Rasio gini 0,30 dan indeks pembangunan manusia 68,74\%.

Upaya pemerintah ini tidak hanyauntuk pemenuhankebutuhan pangan dan ekonomi rakyat saja tetapi juga untuk memenuhi kebutuhan kesehatan atau hidup sehat masyarakat. Karena keragaman konsumsi pangan masyarakatmerupakan unsur utama dalam peningkatan mutu gizi yang diperlukan oleh masyarakat.

Di Kabupaten Pesisir Selatan pada tahun 2010 (survei yang dilakukan oleh Badan Ketahanan Pangan Provinsi Sumatera Barat) skor Pola Pangan Harapan (PPH) ternyata mendapat skor 80,6 \%. Artinya dari perolehan angkatersebut keragaman konsumsi pangan di Pesisir Selatan belum sesuai dengan yangdiharapkan. Hal ini disebabkan oleh tingkat pengetahuanmasyarakat tentang pangan Beragam Bergizi Sehat dan Aman (B2SA) masih rendah. Selain itu tingkat daya beli masyarakat juga rendah.

\section{METODE PENELITIAN}

“Menurut Moleong (2009:6)Penelitian ini merupakan suatu kegiatan yang dilakukan secara terencana dan sistematis untuk mendapatkan jawaban pemecahan masalah terhadap fenomena-fenomena tertentu, maka jenis penelitian ini adalah penelitian kualitatif. Adapun yang 
dimaksud dengan penelitian kualitatif yaitu penelitian yang bermaksud untuk memahami fenomena tentang apa yang dialami oleh subjek penelitian misalnya perilaku, persepsi, motivasi, tindakan, dll. Secara holistik, dan dengan cara deskriptif dalam bentuk kata-kata dan bahasa, pada suatu konteks khusus yang alamiah dan dengan memanfaatkan berbagai metode ilmiah"

\section{HASIL DAN PEMBAHASAN}

\section{Bentuk Partisipasi Kelompok Wanita Tani Dalam Meningkatkan Kawasan Rumah Pangan Lestari.}

Programkawasan rumah panganlestari (KRPL) merupakan suatu program pemerintah melaluiDinas Pangan yang bertujuan membantu masyarakat untuk meningkatkan ekonami dan mutugizi keluarga, sehingga tidak ada lagi keluarga yang terkena gizi buruk. Dengan dibentuknya kelompok wanita tani di setiap kecamatan di Kabupaten PesisirSelatan. Setiap kelompok wanita tani diberi bantuan oleh pemerintah masing-masingnya sebesar Rp. 50 jt yang bertujuan untuk membeli bibit, membangun rumah bibit untuk kelompok, membuat kebun bibit untuk kegiatan pembibitan selanjutnya, dan kegiatan lainnya untuk kebutuhan kelompok.

Kawasan rumahpangan lestari adalah suatu konsep lingkungan perumahan penduduk atau suatu lingkungan aktivitas/tempat tinggalkelompok masyarakat yang secara bersama-sama mengusahakan pekarangan atau lahan sekitar untuk kegiatanbudidaya secara intensif sehingga dapatdimanfaatkan menjadi sumber pangan secara berkelanjutan dalam memenuhi kebutuhan gizi warga setempat terutama gizi keluarga (petunjuk teknis optimalisasi pemanfaatan lahan pekarangan melalui KRPL tahun 2018).

Program KRPL terbentukberdasarkan turunan UU No 18 tahun 2012 berisi tentang pangan, yang menjelaskan dan menekankan pada pemenuhan kebutuhan pangan ditingkat perorangan dengan memanfaatkanpotensi sumberdaya alam, manusia, sosial, ekonomi, dan kearifan lokal secarabermanfaat. Partisipasi kelompok wanita tani al-ikhlas Nagari Sago Salido Kabupaten Pesisir Selatan memberi manfaat yangcukup besar untuk setiap anggota kelompok dalam meningkatkan ekonomi dan mutu gizi keluarga.

Dengan demikian, program KRPL tidak hanyamembantu memenuhi kebutuhan gizi keluarga, namun juga bertujuanuntuk meningkatkan ekonomi keluarga, sehingga tidak ada lagi keluargaterutama anak-anak yang mengalami gizi buruk.

Bentuk partisipasi yang dilakukan anggotakelompok yaitu ikut serta dala setiap kegiatan yang dilakukan seperti ikut serta dalampembuatan kebun bibit, rumah bibit maupun kegiatn rutin anggota kelompok setiap bulannya. 
Pembuatan demplot (demontrasi plot)/ kebun kelompok, digunakan sebagi lokasi percontohan, tempatpraktek dan belajar bagi anggota kelompok dalam usaha budidaya tanaman, sementara itu untuk penanman anggotakelompok membuat bedeng yang digunakan untuk meletakkan tanamanmaupun bibit, selain itu ada jugapemeliharaan ternak ayam buras. Demplot ini ditanam berbagai jenis tanaman seperti sawi, terung, kacang panjang, pitulo, kangkung, tomat, cabe, dan pepaya. Juga hasil ternak ayam buras hasil dari kebun demplot ini selain dikonsumsi jugadijual kepasar dan dananya dijadikan kas kelompok

\section{Pelaksanaan Partisipasi Kelompok Wanita Tani Dalam Meningkatkan Kawasan Rumah Pangan Lestari.}

Dalampelaksanaanpartisipasikelompok wanita tani untuk meningkatkan pengetahuan masyarakat terutama pengetahuan anggota kelompokmengenai program KRPL, bentuk partisipasi tersebutdapat berupa menghadiri pertemuan sosialisasi tentang program KRPL, bagaimanaprogram KRPL dilaksanakan, apa tujuan dari program KRPL itu sendiri dan apa dampakdari program KRPL tersebut terhadapkehidupan anggota kelompok maupun masyarakat kedepannya.

Bagaimanapelaksanaan partisipasi dapat terlaksana dengan baik, maka Dinas Pangan melakukan pelaksanaan dengan metodepenyuluhan, yaitu :

a. Melakukan kunjungantatap muka dengan semua anggota kelompok sesuai dengan rencana yang ditetapkan setiap bulannya dengan metode yang digunakan adalah ceramah dan diskusi tentangpermasalahan yang di alami anggota kelompok.

b. Pelaksanaandemontrasi yang diharapkan untuk seluruh anggota kelompok wanita tani seuai dengan usahakegiatan masing-masing anggota. Demplot yang ada agar dapat menjadi dem area yang berupa suatu kawasan.

c. Pelaksanaansekolah lapangan, yang dilakukan untuk semua anggota kelompok agar lebih menguasai dan terampildalam berusaha tani seperti cabe, semangka,dan tanaman sayuran lainnya.

d.Untuk meningkatkanpengetahuan dan keterampilan anggota kelompok Dinas Pangan memberikan pelatihan baik yangdilaksanakan di kelompok maupun yang dilakukan di kecamatan. Pelatihan disesuiakan dengan kebutuhan anggota kelompok.

Selain itu pelaksanaanpartisipasi juga dilakukan dengan melakukan pemanfaatan lahan pekarangan anggota kelompok. Dimana pemanfaatan ini tidak saja bagian depan rumah tetapi juga bagiansamping dan belakang rumah. Teknik budidaya tanaman menggunakan lahan yang dibuat berupa bedengan dan menggunakan polybek. Jenis tanaman yang di budidayakan di pekarangananggota kelompok dapat diambil dari kebun atau rumah bibit. Yang mana tanaman ini tidak hanya satu 
jenis, tetapiberagam di antaranya sawi, kangkung, terung, kacang panjang, tomat, kunyit, bayam, pitulo dan juga pario yang mana hasil panennya di utamakan untuk konsumsi anggota keluarga kelompok, yang bertujuan untuk meingkatkan kebutuhan gizi keluarga sehingga menu B2SA dapat terwujud. Sedangkan hasil panen yang berlebih dapat dijual untuk menambah pendapatan keluarga.

Selain itu pelaksanaan KRPL juga dilakukan dengan cara melalui demontrasi plot yaitu demonstrasi cara pembuatan kompos jerami, melalui sekolah lapangan dan pelatihan yaitu pelatihan SOP/GAP komoditiunggulan, penangananpasca panen, melalui musyawarah atau rapat bersama pengurus kelompok wanita tani, Wali Nagari, dan seluruh pihak terkait tentang penataan pola tanam, melakukan penilaian kelompok wanita tani, hal ini bertujuan untuk memotivasi semua anggota kelompok untuk berjalan aktif sesuai dengan manajemen kelompok.

\section{Kendala Yang Di Alami Dalam Meningkatkan Kawasan Rumah Pangan} Lestari.

Kedala utama yaitu dari segi teknis dimana belum semua anggota kelompok melakukan pemakaian pupuk yang sesuai dan berimbang pada taaman, pengolahan tanah yang belum sempurna, kurangnya pengetahuan anggot kelompok tentang pemilihan bibit unggul, tidak adanya penanganan dari anggota kelompok untu tanaman yang terserang hama penyakit.

Selain itu kendala yang dialami dari segi ekonomi yaitu anggota kelompok yang tidak memiliki modal untuk usaha dalam bidang pertanian, hasil panen masingmasing anggota dijual dengan harga rendah, tidak adanya pengtahuan anggota kelompok dalam pengolahan hasil panen, terlalu lama proses pasca panen baru terlaksana.

\section{a. Serangan Hama Pada Tanaman Anggota Kelompok}

Tanaman anggota kelompok merupakan KRPL pribadi yang dimiliki masingmasing anggota kelompok, selain berpartisipasi dalam satu kelompok, masingmasing anggota juga di haruskan untuk memiliki KRPL sendiri di pekarangan mereka sendiri, hal ini bertujuan untuk mengoptimalkan manfaat dari program KRPL itu sendiri. Sehingga apabila KRPL yang di tanam anggota kelompok dipekarangan mereka sendiri panen maka hasil panen tersebut dapat dimanfaatkan secara pribadi, sedangkan KRPL yang dimiliki untuk kelompok hasil panennya akan dimasukkan kedalam kas kelompok dengan tujuan untuk pembibitan tanaman selanjutnya.

Serangan hama yang sering dialami anggota menjadi kendala utama kurang maksimalnya hasil panen dari KRPL anggota, karena tanaman sayuran anggota yang sering mati menyebabkan kerugian bagi anggota maupun kelompok. Tidak 
hanya dikarenakan serangan hama, cuaca yang cukup panas pun menjadi faktor selanjutnya yang menjadi kendala bagi anggota untuk meningkatkan KRPL.

Kondisi cuaca yang cukup panas yang mengakibatkan tanaman cepat layu, dikarenakan letak dari Nagari Sago Salido itu sendiri yang dekat dengan pantai, hal ini menyebabkan cuaca cukup panas dan kondisi tanah yang cepat kering menyebabkan tidak semua tanaman mampu bertahan dan akhirnya mati tanpa bisa dipanen.

\section{b. Kurangnya Ketersediaan Bibit}

Selain serangan hama dan cuaca panas, kurang tersedianya bibit juga menjadi kendala selanjutnya yang menyebabkan terhambatnya peningkatan program KRPL. Dalam program KRPL, bibit merupakan hal utama yang harus selalu ada untuk kebutuhan anggota maupun kelompok, oleh karena itu disetiap kelompk KRPL diharuskan adanya kebun bibit, rumah bibit, dan demplot bertujuan agar anggota kelompok tidak kekurangan bibit setelah masa panen.

Kurangnya penyediaan bibit untuk kebutuhan pekarangan anggota kelompok ini terjadi karena kurang cekatannya anggota kelompok untuk berinisiatif melakukan pembibitan sebelum panen dilakukan, sehingga tidak menimbulkan kekosongan pada lahan pekarangan anggota kelompok.

Masalah seperti ini sering dialami anggota kelompok, karena menyebabkan tidak ada lagi bibit yang harus ditanam di lahan pekarangan anggota, hal ini juga menjadi penyebab terlambatnya proses panen selanjutnya karena kekosongan lahan yang di alami anggota kelompok.

\section{c. Kurangnya Sikap Disiplin Anggota Kelompok.}

Sikap disiplin juga menjadi sikap utama yang harus dimiliki anggota kelompok, agar suatu kegiatan dapat berjalan dengan baik dan sesuai tujuan. Disiplin berjuan agar setiap kegiatan yang dilakukan berjalan dengan baik,

Kurangnya sikap disiplin yang ada pada anggota kelompok menjadi kendala selanjutnya yang menjadi faktor penghambat meningkatkan program KRPL. Kurang disiplinnya anggota menjadi penyebab silitnya menjalankan kegiatan-kegiatan rutin kelompok, seperti rapat anggota yang di adakan setiap 2 kali dalam sebulan, kegiatan gotong royong untuk membersihkan kebun bibit dan rumah bibit juga tidak terlaksana dengan baik, termasuk kegiatan pembibitan atau penanaman bibit untuk kegiatan selanjutnya juga tidak terlaksanak dengan baik. Olehkarena itu sering terjadi kekurangan bibit untuk ketersediaan kegiatan anggota ditahan selanjutnya setelah proses panen dilakukan.

\section{d. Pekerjaan Lain Anggota.}


Selain tergabung dalam anggota kelompok wanita tani al-ikhlas, anggota kelompok juga memiliki pekerjaan lain seperti menjadi buruh tani di sawah, ibu rumah tangga, dan ada juga yang bekerja sebagai guru, hal ini menjadi kendala untuk anggota dalam berpartisipasi dalam setiap kegiatan rutin kelompok karena jadwal yang tidak sesuai atau anggota yang bekerja di waktu yang sama.

Hal ini juga menyebabkan kendala karena disetiap kegiatan rutin dilakukan anggota kelompok lebih mengutamakan pekerjaannya dibandingkan mengikuti kegiatan kelompok, olehkarena itu setiap kegiatan rutin seperti rapat anggota kelompok dilakukan tidak semua anggota kelompok hadir dalam kegiatan tersebut.

\section{PENUTUP}

\section{KESIMPULAN}

Berdasarkan temuan penelitian, dapat ditarik kesimpulan sebagai berikut :

1. Bentuk partisipasi yang dilakukan anggota kelompok seperti ikut serta dalam setiap kegiatan yang di lakukan kelompok, wajib ikut sarta dalam rapat rutin yang di adakan kelompok setiap bulannya.

2. Pelaksanaan partisipasi anggota kelompok berjalan dengan baik, dengan adanya bantuan dari Dinas Pangan, pelaksanaan tidak hanya melibatkan anggota kelompok tetapi juga melibatkan langsung anggota dari Dinas Pangan untuk terjun langsung ke lapagan.

3. Kendala yang menjadi penghalang dalam meningkatkan program KRPL seperti serangan hama, kurang disiplinnya anggota kelompok, kurangnya ketersediaan bibit, dan adanya pekerjaan lain anggota kelompok diluar kegiatan kelompok.

\section{DAFTAR PUSTAKA}

Badan Pusat Statistik Kabupaten Pesisir Selatan 2013. Kabupaten Pesisir Selatan Dalam Angka 2013. Kabupaten Pesisir Selatan. Badan Pusat Statistik.

Kementerian Pertanian RI Badan Ketahanan Pangan 2018, petunjuk teknis pemanfaatan lahan pekarangan melalui kawasan rumah pangan lestari. Pusat Penganekaragaman Konsumsi dan Keamanan Pangan.

Maleong, L.J. 2009. Metode Penelitian Kualitatif. PT Remaja Rosda Karya. Bandung

Mikkelsen, Britha. 2003. Metode Penelitian Partisipatoris dan Upaya-Upaya Pemberdayaan.Penerbit Alfabeta. Bandung.

Purawouw, R., 2016. Peran Tokoh Masyarakat dalamMeningkatkan Partisipasi Pembangunan (studi di Kelurahan Duasudara Kecamatan Ranowulu Kota Bitung). Jurnal Politico UNSRAT, Vol 3. No 1. ISSN :2302-5603. Hal 1-17. 


\section{EDUNESIA}

Indonesia Jurnal of Education Research

Sugiyah. (2010). Partisipasi Komite Sekolah dalam penyelenggaraan

Rintisan Sekolah Bertaraf Internasional di Sekolah Dasar Negeri IV Wates, Kabupaten Kulon Progo. Tesis. PPs UNY.

Yuwono, T. 2001. Manajemen Otonomi Daerah: Pembangunan Daerah Berdasarkan Paradigma Baru, Clogappss. Universitas Diponegoro. Semarang.

Van Den dan Hawkins. 1999. Penyuluhan Pertanian. Kanisius. Yogyakarta.

Undang-Undang Nomor 18 tahun 2012 tentang Pangan 